\title{
La «Gloria de Niquea» y la «Torre del Universo»: dos edificaciones mágicas subordinadas al ars narrandi de Feliciano de Silva
}

\author{
«Gloria de Niquea» and «Torre del Universo»: Two Magical Buildings \\ Subordinate to Feliciano de Silva's Ars Narrandi \\ Julia Navarro Hermoso \\ (Universidad de Jaén)
}

\begin{abstract}
RESUMEN
El artículo estudia un tema relacionado con las obras caballerescas de Feliciano de Silva: la construcción de los episodios mágicos. Se analizan en concreto dos aventuras incluidas en Amadís de Grecia y Florisel de Niquea (I): «La Gloria de Niquea» y «La Torre del Universo». Se seleccionan estos episodios por ser claves en la trama y por representar la artificialidad de las construcciones mágicas. Ambos contienen un significado y una función narrativa que se desarrollan en la trama argumental de las dos obras, y que permiten posicionar a Silva, debido al tratamiento literario que otorga a estas aventuras, como autor plenamente renacentista.
\end{abstract}

\section{Palabras Clave}

Feliciano de Silva, Amadís de Grecia, Florisel de Niquea, autor renacentista, construcciones mágicas, función narrativa, artificio, magia.

\footnotetext{
Abstract

This article aims to study a subject related with the chivalric plays of Feliciano de Silva: the construction of magical episodes. Two adventures included in Amadís de Grecia and Florisel de Niquea (I) will be analysed: «La Gloria de Niquea $\gg$ and «La Torre del Universo». We have selected these episodes because they are keys to the plot and represent the artificiality of magical constructions. Both episodes contain a meaning and a narrative function that are developed in the plot of the works. These achievements, due to the literary treatment he gives to these adventures, allow Silva to be positioned as a fully Renaissance author.

KEYWORDS

Feliciano de Silva, Amadís de Grecia, Florisel de Niquea, Renaissance author, magical constructions, narrative function, artifice, magic.
}

Recibido: $25 / 06 / 2020$

Aceptado: 13/10/2020

Tirant, 23 (2020), pp. 167-176

DOI: $10.7203 /$ tirant.23.19117 


\section{Líneas narrativas fundamentales en Amadís de Grecia}

La magia en los libros de caballerías es un tema que ha sido ampliamente estudiado por parte de numerosos expertos, pero es importante destacar que los trabajos que encontramos al respecto están centrados mayoritariamente en objetos mágicos, personajes auxiliares fantásticos, profecías, etc. Buen ejemplo de ello son los estudios de Mérida (2001), que investigó en profundidad el Amadís de Gaula y la magia presente en la obra; Alvar (1991), que hizo un minucioso análisis sobre las hadas como seres que benefician a los héroes; Nasif (2009), que ha clasificado en varias ocasiones los elementos mágicos; o González (2002), cuyo acercamiento a los vaticinios en los libros de caballerías le han llevado por derroteros más teóricos acerca de los mundos reales, posibles e imposibles en relación con los discursos proféticos.

Ante este sintético panorama crítico, resultan escasos los trabajos que profundizan en otras obras, como aquellas en las que se centrará este estudio. El tema de la presencia de la magia como elemento constructivo en los libros caballerías resulta bastante complejo y atractivo, porque nos permite ver más allá de lo escrito y tratar de comprender las razones que llevaron al autor a usar una determinada estructura en un momento dado en la obra. Concretamente nos ceñiremos a dos textos del ciclo amadisiano: Amadís de Grecia (1530) y la Primera Parte de Florisel de Niquea (1532), ambos del mirobrigense Feliciano de Silva. Como se sabe, Silva optó, entre las dos vertientes que surgieron en la época (Sales Dasí, 1997: 199), por la más heterodoxa, apostando por la fantasía y la imaginación por encima de la moralidad y la fe. Es precisamente a partir de Amadís de Grecia (1530) cuando Silva da muestras de la modernidad de su narrativa, ya que con su Lisuarte (1514) se había adaptado a las reglas marcadas por sus antecesores. Sin embargo, en las dos obras que analizaremos logra sumergir al lector en un mundo maravilloso donde prima la teatralidad y el humor (García Álvarez, 2015a).

El objetivo de este estudio es profundizar en dos aventuras mágicas que son fundamentales en el ciclo amadisiano, porque representan la complejidad creativa y, a la vez, el ingenio narrativo presente en la obra de Silva. Como prueba de esta originalidad encontramos las grandes puestas en escena que se pueden observar en las aventuras mágicas que el autor crea desde Amadís de Grecia; recordemos que fue a partir de entonces cuando verdaderamente dota a sus obras de componentes de magia y fantasía. Asimismo, llama la atención la minuciosidad con la que describe cada uno de los escenarios en los que se desarrollan las aventuras y cómo los personajes encargados de protagonizarlas van dejando su personal huella en las mismas. Las aventuras en las que nos centraremos son la Gloria de Niquea y la Torre del Universo. Ambas, aunque con finalidades distintas, son claves en las trayectorias vitales de los personajes porque, además de reunir a los principales, muestran claramente quiénes serán los elegidos para superar las pruebas y así dar continuidad a las aventuras del linaje de Amadís.

Ahora bien, antes de profundizar en ambas construcciones episódicas, es importante delimitar el concepto de «aventura» en los libros de caballerías. Las aventuras, entendidas como historias delimitadas, se insertan dentro de la estructura de los libros de caballerías de tal forma que se podrían considerar como la unidad básica de acción (Marín Pina, 1989: 150). Si la entendemos así, parece obvio que se trate, entonces, de una pieza narrativa fundamental del género caballeresco, puesto que en realidad es la «unidad mínima generadora de las distintas secuencias narrativas» (Marín Pina, 1989: 152) y a partir de ella se creará todo un universo de redes y tejidos ficcionales. Puesto que hemos considerado la aventura como unidad mínima, esto supone que debe tener, en sí misma, su propia estructura narrativa a nivel interno, por lo que constará de un inicio, un nudo 
y un desenlace, como veremos a lo largo de este trabajo, algo que será sumamente relevante para el desarrollo de la acción de las edificaciones mágicas aquí analizadas.

\section{La incertidumbre de la Gloria de Niquea}

La aventura de la Gloria de Niquea se produce en un momento crucial de la Segunda Parte de Amadís de Grecia, puesto que surge cuando Niquea ha enviado al enano Busendo a mostrarle el pergamino con su figura al caballero de la Ardiente Espada. Es, entonces, cuando ella, preocupada por si su amado está interesado en otra dama y animada por su padre, decide pasar unos días en la casa del bosque. Sin embargo, ese inocente gesto desencadenará toda una serie de acontecimientos en la obra porque un día, mientras Niquea se encuentra en una fuente descansando del largo

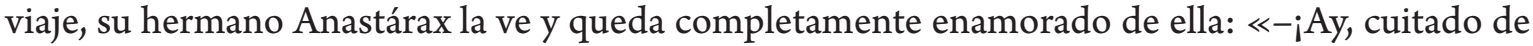
ti, Anastárax! ¿Adónde está el tu bravo coraçón que tan súpitamente á sido forçado y vencido con sola la vista de una donzella? A donde, si ella remediar no te quiere, te conviene passar por la más cruda muerte que nunca cavallero passó» (Silva, 2004: 311). Será este hecho lo que marque un antes y un después en el destino no solo de los hermanos, sino también del resto de los personajes de la obra porque se produce la entrada en escena de la maga Zirfea, quien consciente del peligro de este amor prohibido que ha surgido en Anastárax, visita a su hermano, el Soldán (padre de Niquea) y le ofrece una solución: el encantamiento de la Gloria de Niquea.

En esta aventura mágica la protagonista será Niquea y desde el comienzo todo parece indicar que el encargado de resolverla sería Amadís de Grecia, pero la realidad es que Silva logra, una vez más, sorprender al lector debido a la disposición que otorga al episodio. Zirfea, llevando con ella a Anastárax y a Niquea, construyó la prueba de la siguiente manera: en primer lugar, eligió una de las cuadras del castillo y allí hizo un estrado con quince gradas cubiertas de paños de oro, colocando sobre este un cobertor sostenido por cuatro pilares de cristal y debajo una silla convenientemente adornada. Más tarde vistió a Niquea con una ropa muy rica, le puso una corona de oro con mucha pedrería y la invitó a sentarse en la silla. La joven obedeció y fue entonces cuando Zirfea llamó a dos doncellas y les ordenó que sostuviesen un espejo que ella misma les dio y lo mantuviesen delante de Niquea:

Como ellas lo hizieron, Niquea puso los ojos en él, en el cual súpitamente le pareció ver en él al Cavallero de la Ardiente Espada grande y tan natural como él lo era, recibiendo tanta gloria en verlo, que le parecía no poder aver más de la que ella tenía. [...] La hermosa Niquea [...] quedó tan desacordada, que en ál no tenía su pensamiento mas de en aquello que presente tenía (Silva 2004: 313).

A partir de ese momento, en la cuadra se produjeron toda clase de sonidos de aves, doncellas cantando y tocando el harpa, flores cubriendo el suelo y las paredes se volvieron de cristal, donde estaban reflejadas todas las historias de amor que se habían dado en el mundo. Como se puede intuir, al tratarse de una prueba mágico-amorosa, no todos iban a poder acceder a ese lugar, así que la maga impuso ciertas condiciones:

Puso tal encantamiento que ningún cavallero pudiesse subir por ellas [las gradas] arriba más de como se estendiesse su bondad, ni ninguna donzella más de cuanto se estendiesse la lealtad que en bien amar avía tenido, y hasta llegar al merecimiento de cada uno y cada 
una se estendiesse no pudiesse ser vista Niquea, y que, como allí llegassen, sintiessen tanta gloria, como si en el paraíso estuviesen (Silva 2004: 314).

Inmediatamente después, Zirfea hizo entrar en la cuadra a Anastárax y lo invitó a subir las gradas. Él se quedó a solo dos escalones de donde estaba Niquea y desde allí pudo ver todo cuanto tenía a su alrededor y, tomando un harpa, comenzó a tañer y a cantar admirando a su bella hermana. Entonces la maga terminó de hacer sus conjuros: «Niquea, aí estarás hasta tanto que venga aquel que por ser estremado en bondad y lealtad de amores merezca gozar de la gloria y te sacara d'ella con todos los que hasta entonces con tu vista la ternán» (Silva, 2004: 314). Y posteriormente se dirigió a Anastárax con estas palabras: «Aí estarás gozando de la gloria que tienes hasta que Niquea de aquí salga, y desde aquel punto quedarás en tinieblas hasta que venga aquella tan estremada en hermosura que, con el resplandor de su hermoso gesto, el verdadero amor que en Niquea tenías en ella todo lo mudarás» (Silva, 2004: 314).

Con el encantamiento finalizado, Zirfea salió de la cuadra e hizo a las puertas del castillo una llama de fuego que todos deberían atravesar si deseaban probar la aventura. Sobre ella colocó una inscripción: «Ninguno ni ninguna sea tan osado de entrar a ver la Gloria de Niquea sino aquel o aquella que por el merecimiento de su lealtad de amor secreto mereció gozar d'ella, porque ansí se lo amonesta Zirfea, reina de Árgenes, que el presente encantamiento con su saber hizo» (Silva, 2004: 314). Con este rótulo la maga pretendía que solo aquel caballero que fuese completamente leal a su dama completara la aventura al ser el elegido para superarla, por lo que adivinamos ya que Amadís de Grecia quedaba descartado al debatirse entre dos damas.

La función de la magia en el encantamiento de la Gloria de Niquea consiste en la resolución de un conflicto. Como se sabe, nada en los libros de caballerías sucede al azar, por lo que podemos intuir que Silva, a la hora de configurar como se desarrolla la aventura, sabía perfectamente que el encuentro entre Anastárax y Niquea haría obligatoria la presencia e intervención de Zirfea y, por tanto, de la magia. Hay que recordar que en los libros de caballerías del ciclo amadisiano a menudo encontramos que, para iniciar una aventura mágica, ya tenga como objetivo ensalzar la honra y el valor del héroe, ya sea con fines amorosos (recordemos, por ejemplo, la aventura del Arco de los Leales Amadores en Amadís de Gaula), la presencia del encantamiento es indiscutible, puesto que es el elemento que va a servir para poner en movimiento la acción y para que los acontecimientos se vayan sucediendo. En este caso el autor se sirve de dicho encuentro para poner en funcionamiento el mecanismo mágico que conllevará, supuestamente, la unión de los enamorados.

La Gloria de Niquea constituye una aventura mágica que cobra especial relevancia dentro de la obra, no solo porque convoca a un gran número de caballeros que van a intentar probarla, sino porque coloca en el centro de la trama a la dama: Niquea. No estamos, por lo tanto, ante una obra estructurada como las anteriores, en la que encontrábamos a una pareja protagonista que ya venía perfilada desde el comienzo. A partir de una nueva concepción del oficio narrativo, Silva establece una refuncionalización de las pruebas amorosas, mostrando así su carácter innovador, al manipular un material tópico de las novelas de caballerías para complicar la trama y causar más expectativas en el público: esta aventura no constituye la unión de los enamorados, sino una etapa más en su trayectoria amorosa. De esta manera, el autor da muestras de una modernidad estilística, al manipular materiales sobradamente conocidos por el público y a los cuales decide dotar de una función más innovadora con el fin de otorgar mayor dramatismo a la historia. En esta continuación amadisiana los protagonistas se van a ir abriendo paso entre infinidad de personajes y aventuras, y se enfrentarán a diversos peligros, dificultades y desavenencias hasta lograr su unión. Es 
importante destacar que esta aventura tiene como base la construcción de un castillo encantado y que se adscribe al motivo de la ordalía en los libros de caballerías (Duce García, 2005: 229). Resulta muy interesante, en ese sentido, el acercamiento que hace Bueno Serrano (2007) al respecto.

En el episodio vamos a encontrar un nutrido número de personajes, pero también de elementos misteriosos o maravillosos como es el caso del anillo que obtuvo el rey Montón de la Liça. En una de las ocasiones en la que Amadís de Grecia se dirigió hacia el territorio donde se encontraba Niquea con intención de completar la aventura, preguntó a una doncella:

- Sabed, mis señores -dixo ella-, que avía quinze días que llegó a provar la Gloria de Niquea el rey Montón de la Liça, el cual tuvo poder de entrar y gozar de ver la gloria y gran hermosura de Niquea, y por virtud de una sortija que un sabio le embió pudo tornar a salir donde ninguno que entrasse jamás lo pudo hazer, que es cosa de maravillar de lo que cuenta assí de su gran hermosura como de la gloria que allá se siente (Silva 2004: 361$362)$.

Gracias a esta desconocida doncella, conocemos la capacidad del anillo: ofrecía al rey la opción de entrar y salir de la Gloria de Niquea sin impedimento alguno. Este hecho supuso que el rey se mantuviera como fiel defensor de aquella aventura y no permitiera el paso a ninguno de los caballeros que intentaban probarla. Se producía así una batalla en la que los caballeros luchaban y siempre el de la Liça resultaba vencedor. Sin embargo, desconocemos qué ser mágico le otorgó el anillo al rey incluso al final de la obra, por lo que se trata de un elemento envuelto en un halo misterioso, dotado de propiedades que beneficiaban a su dueño, pero que impedía el transcurso normal de la prueba mágica. $\mathrm{Y}$ es precisamente ese misterio el que lo erige como un recurso muy conveniente para nuestro autor, quien de nuevo se sirve de un motivo común en los libros de caballerías, aunque modificándolo, para complicar la trama y enriquecer el desarrollo de la acción narrativa.

En cuanto a la superación de la prueba, el lector da por hecho que sería Amadís de Grecia el encargado de completarla, pero Silva, como ya señalamos, logra sorprendernos. Y es que resulta revelador observar cómo el autor consigue, gracias a su innovación, no solo mantener a sus lectores en vilo con la historia del linaje amadisiano, sino también impresionar con sus giros compositivos inesperados, frente a lo que sucedía en obras anteriores, que normalmente seguían un mismo patrón. En este caso hay dos ocasiones en las que, estando en la entrada de la Gloria de Niquea, ante el gran fuego, el caballero de la Ardiente Espada no supera la prueba. La primera vez decide no arriesgarse, porque lee la inscripción de la entrada (recordemos que el requisito indispensable para probar la aventura era la lealtad en el amor) y el caballero llega a la conclusión de que, debido a sus dudas sobre Luscela y Niquea, probablemente se sería dañado por el fuego, por lo que decide abandonar la idea de intentarlo. Y la segunda se lo impide una doncella de la emperatriz Abra, quien lo estaba esperando para ir a Trapisonda a vengar la muerte de Zair, el hermano de la emperatriz.

La tercera y última vez que Amadís de Grecia acude a la Gloria de Niquea, la aventura ya había finalizado y el encargado de culminarla fue el veterano Amadís de Gaula: «cuando el rey Amadís supo las letras del padrón, confiando en su gran bondad y lealtad, dixo que por cosa del mundo no dexaría de provar el aventura» (Silva, 2004: 435). No obstante, el rey Amadís tuvo que enfrentarse a Montón de la Liça, que permanecía inamovible en la entrada defendiéndola de cualquier intruso. Pero el rey de la Liça cometió un error al intentar rehuir de la batalla entrando en la Gloria, pues no esperaba que el de Gaula lo siguiera y lograra completar la aventura. Una vez dentro, 
el rey de la Gran Bretaña le cortó la cabeza al de la Liça y esto provocó que, de repente, todos los que se encontraban en la Gloria de Niquea recuperaran la cordura:

\footnotetext{
El espejo que las infantas tenían puesto ante Niquea [...] de las manos con el golpe fue sacado, y como dio en el estrado, fue todo quebrado. Como el espejo se quebró, Niquea quedó en todo su acuerdo, y assí lo hizieron los que dentro de la cuadra estavan. [...] Grande fue el gozo del rey en aver dado fin a tan grande aventura y la pena de Niquea doblada en averle quitado de la gloria en que estava, y assí lo fue de todos los que fueron desencantados (Silva 2004: 436).
}

Amadís de Gaula consigue superar la prueba y con la finalización de la aventura, el lector recuerda los inicios de la saga y redescubre cómo la figura principal del linaje aún estaba en condiciones de resolver conflictos que, recordemos, solo podía superar aquel que había sido leal en el amor. En este sentido, es indiscutible el hecho de que Silva no desea renunciar a la vieja caballería, sino que la defiende (Cravens, 2000: 51-69). Hay que tener en cuenta que la vertiente más ortodoxa de las dos que surgieron en torno a los libros de caballerías, aquella que colocaba en el centro de atención la fe, había sido tajante en ese sentido. Tanto Juan Díaz como Páez de Ribera se encargaron de desprestigiar a Amadís de Gaula y relegarlo a un segundo plano. Nuestro autor toma otros derroteros que lo llevarán a ensalzar su figura y a colocarla, como en esta ocasión, en el centro de la acción como acto de celebración y homenaje a esa vieja caballería que representaba los valores absolutos: la honra y la lealtad a la dama.

Antes de adentrarnos en la siguiente aventura, es fundamental señalar que el final de la Gloria de Niquea supone el inicio de otra prueba mágica: el Infierno de Anastárax, que tendrá su resolución en obras posteriores. Resulta llamativo observar cómo Silva es capaz de entrelazar ambas aventuras de tal manera que el final de la primera suponga el comienzo de la segunda. El papel aquí del entrelazamiento es innegable. Mediante esta técnica, el autor construye un entretejido narrativo que nos conduce a pensar que ambas aventuras se encuentran en el mismo nivel de importancia dentro de la estructura de la obra y que, además de tener una función específica, las dos contarán con la intervención de los protagonistas para resolverse. Sin embargo, en este caso Silva no se acogerá a la técnica tradicional que ya estudiara Cacho Blecua (1986: 235-271), sino que, dotando a su obra una vez más con un marcado carácter innovador, acude a nuevos giros narrativos que lo erigen como un autor que busca un estilo de variación, pero sin alterar el modelo de equilibrio y armonía del mundo caballeresco amadisiano. Este uso especial del entrelazamiento, al que ya se refirió García Álvarez (2015b), sirve al autor para dar continuidad a la historia y no interrumpir el devenir narrativo, puesto que las aventuras se sucederán implicando a distintos personajes, pero dando impresión de simultaneidad para hacer verosímil la ficción.

\section{El encantamiento de la Torre del Universo: la aventura clave de la opera prima del ciclo de los Floriseles}

La aventura de la Torre del Universo se sitúa en un momento de la obra en el que la mayoría de los protagonistas se encuentran en Trapisonda, inmersos en la resolución de otra prueba mágica: el Castillo de las Poridades. Es entonces cuando Zirfea acude a ver a los sabios Alquife y Urganda sobre un carro volador guiado por grifos y en medio de una gran nube negra de rayos y relámpagos, y mostrándoles sus buenas intenciones gracias a la ayuda prestada a su hija Axiana, 
los invita a ir con ella para contarles lo que había pensado crear, para lo que necesitaba contar con su colaboración. Antes de que la maga pudiera informarles de lo que pensaba construir y de sus razones, llevó a los sabios a visitar la Gloria de Niquea y ambos se quedaron impresionados con aquella aventura y, aún más, con la hermosura de Niquea. Incluso Alquife y Urganda también permanecieron absortos ante esa gloria de la que todos los que estaban dentro gozaban y Zirfea, mediante sus artes mágicas, tuvo que devolverles la cordura. Mostrarles esa prueba fue señal de buena voluntad por parte de la reina de Árgenes, que hasta entonces se había mostrado hostil hacia los sabios y hacia los protagonistas de la saga. Después de ver la Gloria de Niquea, Zirfea llevó a los sabios con su hermano el Soldán y les contó lo que pretendía erigir: «Vamos a que se acabe una obra. Sería la más estraña que se vio para que gozemos todos de la gloria de aver acabado tan gran cosa y para dar claridad a todos los que vienen en el mundo que la quisieren recebir, la cual, aun yo, hasta acabada no puedo conocer» (Silva, 2004: 424).

Para la construcción de la Torre del Universo fue necesaria la intervención de los tres seres mágicos más sobresalientes de la saga, por lo que podemos intuir que se tratará de una edificación mágica muy significativa, que marcará la vida y, obviamente, los destinos de los protagonistas y los suyos propios. Los tres sabios se reunieron durante la noche en una parte de la ciudad de Niquea, donde había un puente, y formando un triángulo y con velas encendidas, comenzaron a recitar sus conjuros provocando un temporal de rayos, truenos y relámpagos. Antes del amanecer habían construido una torre: «la más grande y hermosa que jamás se vio, ansí por de fuera como por de dentro. Eran en ella siete cuadras que no tenían precio su riqueza y valor, cada una encima de otra» (Silva, 2004: 424). Cada una de las cuadras estaba dedicada a un dios: la primera a la diosa Diana; la segunda al dios Mercurio; la tercera al dios Mares; la cuarta a la diosa Venus y el dios Cupido; la quinta al dios Febo; la sexta al dios Júpiter; y la séptima al dios Saturno. Pero lo más importante quedaba contenido en lo más alto: «estava en el aire un Mundo a manera de poma muy grande con todas las partidas, ínsulas y mares, [...] sobre el cual estava en un carro triunfal la Muerte con un arco y muchas flechas» (Silva, 2004: 425). Ante la gran majestuosidad de la Torre, todos quedaron sorprendidos, pero Zirfea señaló que aún faltaba el detalle más importante: «Agora veremos una gran cosa para dar perfición a esta obra, y es que nombrando todos los dioses uno a uno y nombrando Aquel que tiene poder sobre todos, parecerá en su triunfal carro sobre todos los cielos, y los moverá haziendo sus influencias naturales en cada parte del universo según sus operaciones» (Silva, 2004: 425). Sin embargo, cuando recitó sus conjuros en voz alta, nada sucedió, así que invitó a Alquife a conjurarlo, pero en nombre de su Dios y, al hacerlo, apareció el mejor Cielo que habían visto jamás y Dios sobre un carro. Cuando Zirfea observó lo ocurrido, no dudó en renegar de sus dioses y abrazar la fe cristiana.

Posteriormente, decidieron colocar sillas en cada cuadra para que aquellos grandes señores que en algún momento futuro se encontrarían ahí, estuvieran lo más cómodos posible hasta que por una aventura mágica fuesen liberados y, a la entrada del Castillo del Universo, como se conocerá a partir de entonces, colocaron un padrón cuya inscripción decía: «[...] Esta es la morada del Universo Mundo, donde su secreto estará para todos escondido hasta que por grande aventura a él vengan los dos justos merecedores de su señorío, y hasta estonces gozar se an sus aposentos de todas sus maravillas» (Silva 2004: 425). Una vez construida la Torre, Zirfea se la mostró al Soldán, le entregó las llaves y los tres sabios partieron hacia la ínsula de Árgenes.

La construcción de este Castillo provocará una serie de acontecimientos a lo largo de la obra y será el centro de la acción en diversos momentos de la trama. Recordemos que se trata de un artificio realizado por los tres sabios y que, además, guardaba en su interior el funcionamiento y 
los misterios del mundo. Una de esas ocasiones en las que se convierte en el principal foco de acción es cuando el Soldán de Niquea, profundamente enamorado de Nereida (que era en realidad Amadís de Grecia disfrazado de doncella), pero ignorado por ella, decide arrestarla y encerrarla en el Castillo del Universo. Allí Nereida sufrirá pensando en su amada Niquea y un día, cansada de la prisión, decidirá subir al lugar más alto de la Torre:

como encima fue, luego el mundo y los cielos le fue representado y sus movimientos. Ella quedó tan espantada de lo ver, que de cosa jamás no lo fue más, y miró en lo alto de todos los cielos y vio el carro triunfal en que el solo soberano Señor estava; luego le vino conocimiento claro del engaño que hasta allí avía tenido, y, hincando los hinojos en tierra, lo adoró renegando de los dioses que hasta allí avía tenido, prometiendo en servicios de lo enmendar (Silva 2004: 459).

De esta manera, Nereida no solo descubre y se convierte, como ya hiciera Zirfea, a la fe cristiana, sino que además observa y conoce lo que está sucediendo en el mundo y las numerosas batallas y guerras que están produciéndose, y es entonces cuando halla el engaño de Balarte, quien gracias a un agua mágica tomó la apariencia de Amadís de Grecia, porque deseaba por encima de cualquier cosa poseer a Niquea. La Torre del Universo, por tanto, cumple aquí la función de revelar un conocimiento totalizador y verdadero porque, además de mostrar a Amadís de Grecia, hasta entonces pagano, quién es el Dios verdadero, también descubre el gran engaño en el que todos están cayendo, pensando que el príncipe Balarte es Amadís de Grecia.

Pero para la resolución de esta gran aventura habrá que esperar a la Primera Parte de Florisel de Niquea, donde los dos héroes elegidos, en este caso Florisel y Anaxartes, hijos de Amadís de Grecia, culminarán la prueba al reunirse y luchar:

como ellos cayeron, de los yelmos de los cavalleros que en tierra estavan salen súpito tal claridad que no parescía sino que dos verdaderos soles fuessen, y con sus radiantes rayos comiença a romper por las nieblas del universal castillo, de suerte que assí corrompían por ellos, como el sol por las terrenales suele hazer con la fuerça de su calor (Silva 2015: 191).

Esta claridad, que provocó el encuentro de los hermanos destinados a finalizar la prueba, logra deshacer los conjuros que contenía el Castillo y, de esta manera, aparecen en un carro tirado por dragones los tres sabios (Zirfea, Alquife y Urganda) y vuelven en sí aquellos grandes señores (Amadís de Gaula y Oriana, Esplandián y Leonorina, Lisuarte, Gradafilea y Abra entre muchos otros) que estaban bajo encantamiento en el interior. Cuando todos recuperaron la cordura, la maga Zirfea explicó a Lisuarte quién era Silvia (aquella hija que él creía perdida pero que el destino había llevado justamente a ese lugar) y ambos se abrazaron después de haber pasado toda la vida separados. Asimismo, una vez que todos se saludaron después de estar hechizados, acudieron a ver quiénes eran los caballeros que habían logrado deshacer tal encantamiento: Florisel y Anaxartes estaban cuerdos, y no recordaban qué había ocurrido y quiénes eran esas personas, así que los sabios se encargaron de contárselo, explicando a todos las profecías que habían vaticinado ese día.

Como podemos observar, la Torre del Universo no solo revela la verdad a Zirfea y a Amadís de Grecia acerca de su fe, sino que además, en la culminación de la prueba, la verdad surge e ilumina a todos los personajes que hasta entonces habían estado bajo encantamiento e ignorancia por su estatismo. La magnitud de este artificio mágico es inmensa, porque incluso indica Silva que: «por 
virtud de los yelmos y su claridad, que fue tanta que no solo su fuerça pudo deshazer la de la Torre del Universo, mas la de las Maravillas de Amor. En aquel día fueron todos sus encantamientos deshechos, con los de la Cueva de Melía» (Silva, 2015: 193). El conjuro del Castillo del Universo fue tal que incluso deshizo algunos anteriores. Ahora bien, atendiendo a la dimensión del encantamiento y a la función narrativa que cumple la magia en este caso, que es la revelación de la verdad, podríamos preguntarnos si no supone una especie de profecía encubierta, dado que normalmente dicha acción formaría parte de la tarea de los sabios como seres mágicos auxiliares que iluminan a los protagonistas ante un suceso particular. Sería interesante observar la presencia de artificios así a lo largo de la obra para comprobar si se dan las pautas necesarias para considerarlos como tal.

\section{Conclusiones}

Como hemos podido apreciar, el estudio de las funciones narrativas de la magia resulta complejo y variable. Con respecto a la primera aventura que analizamos, la Gloria de Niquea, señalamos que la magia cumple fundamentalmente la función de resolver un conflicto. En este caso, la intervención de la maga Zirfea será imprescindible para el desarrollo de la trama y para encauzar el destino de los protagonistas. Por otro lado, el Castillo del Universo, además de erigirse como un artificio mucho más sofisticado y para cuya construcción fue necesaria la colaboración de los tres sabios, sirvió como fuente de revelación de la verdad.

Las obras seleccionadas y las dos aventuras a las que nos hemos acercado reflejan parte de la infinita creatividad de un autor que escoge y estudia minuciosamente qué papel va a desempeñar la magia en cada momento y lo plasma sobre la obra con un estilo plenamente renacentista. Son de vital importancia las innovaciones narrativas que presenta Silva gracias a su concepción mucho más abierta y amplia que la de sus antecesores, sobre todo en lo referente a la refuncionalización que otorga a tópicos de los libros de caballerías, transformándolos y dándoles un nuevo sentido cuyo fin no es otro que complicar la trama y enriquecer la ficción. Este es el caso de la Gloria de Niquea, en la que el motivo de la ordalía cobra una nueva función y no finaliza con la unión de los enamorados, sino que constituye un escalón más en la trayectoria amorosa de la pareja protagonista.

La Gloria de Niquea plantea una aventura única hasta el momento: Silva describe hasta el más mínimo detalle del artificio que crea Zirfea en esta prueba. Este hecho nos invita a imaginar exactamente cómo podía ser la estructura, lo que ocurría alrededor de la protagonista, cómo era Niquea, entre otros detalles que transportan al lector y oyente, en tiempo presente, al lugar en donde se realiza la acción. Ese marcado carácter teatral, al que Silva se acoge a partir de Amadís de Grecia, se irá perfilando en sus continuaciones, y es que la función del público ya no solo estará centrada en los receptores de la novela, sino también en los propios personajes que, en ocasiones, se convierten en meros espectadores de una aventura ante escenarios fantasiosos y con realidades increíbles.

Asimismo, con la construcción de la Torre del Universo, el autor busca dos objetivos principales: por un lado, la creación de un gran artificio que acogerá a dos héroes elegidos, quienes serán los encargados de culminar la aventura; y por otro, la revelación ante Zirfea y Amadís de Grecia del verdadero Dios. Con la inserción de esta aventura, los sabios van encaminando el destino de los personajes que, aun sin depender de ellos, está íntimamente vinculado con la magia.

Por último, es importante señalar que la presencia de la magia puede tener otras funciones, como la de fomentar el entretenimiento tanto para el lector como para los demás personajes que 
aparecen en el episodio; una puesta en escena de los sabios, ya sea Alquife, Urganda o Zirfea, y para trasladar a los protagonistas, entre otras acciones que van ocurriendo. A lo largo del ciclo se puede observar que las funciones de la magia se van repitiendo, lo cual no significa que la estructura literaria sea la misma o que el autor utilice los mismos mecanismos. Y es que un autor como Feliciano de Silva a menudo nos deleita con giros inesperados que enriquecen la ficción. Aunque aquí solo nos hayamos centrado en dos de sus obras, las continuaciones por él escritas están repletas, como esta, de episodios mágicos que cada vez arrojan más luz al estudio del ars narrandi en relación con la magia en los libros de caballerías, un modo de quehacer literario que, sin duda, excedió de la norma prescrita para este género de prosa de caballerías.

\section{Bibliografía}

Alvar, Carlos (1991), «Mujeres y hadas en la literatura medieval», en Evolución narrativa e ideológica de la literatura caballeresca, ed. María Eugenia Lacarra, Vitoria, Universidad del País Vasco, pp. 21-34.

Bueno Serrano, Ana Carmen (2007), «Una ordalía mágico-amorosa en el Amadís de Grecia de Feliciano de Silva», Voz y letra, 18, 2, pp. 3-28.

Cacho Blecua, Juan Manuel (1986), «El entrelazamiento en el Amadís y en las Sergas de Esplandián», en Studia in honorem prof. M. de Riquer, Barcelona, Quaderns Crema, pp. 235-271.

Cravens, Syney Paul (2000), «Amadís de Gaula reivindicado por Feliciano de Silva», Nueva Revista de Filología Hispánica, 48, pp. 51-69.

Duce García, Jesús (2005) «Fantasías caballerescas: aproximación al motivo de los castillos encantados », en Actas del IX Congreso Internacional de la Asociación Hispánica de Literatura Medieval (A Coruña, 18-22 de septiembre de 2001), eds. Carmen Parrilla; Mercedes Pampín, A Coruña, Universidade da Coruña, Toxosoutos, vol. 2, pp. 213-232.

García Álvarez, Juan Pablo Mauricio (2015a), «Narratividad teatral en Feliciano de Silva», en Estudios de literatura medieval en la Península Ibérica, coord. C. Alvar Ezquerra, San Millán de la Cogolla, Cilengua, pp. 577-592.

(2015b), «Alternativas narrativas para enlazar historias en la Primera Parte del Florisel de Niquea (caps. VI-XXI)», en Literatura y ficción: "estorias", aventuras y poesía en la Edad Media, ed. Marta Haro, Valencia, Universitat de Valencia, vol. 2, pp. 489-502.

GonZÁLEZ, Javier Roberto (2002), «'Profetizar' como acto de habla en los libros de caballerías (a propósito de los discursos proféticos del Primaleón)», Moenia, 8, pp. 223-249.

Le Goff, Jacques (1985), Lo maravilloso y lo cotidiano en el Occidente medieval, Barcelona, Gedisa.

MÉRIDA JimÉnez, Rafael Manuel (2001), Fuera de la orden de natura»: magia, milagros y maravillas en el Amadís de Gaula, Kassel, Reichenberger.

NAsif, Mónica (2009), «Fenomenología del quehacer mágico: su evolución en la literatura caballeresca castellana $\gg$, Letras, 59-60, pp. 275-282.

Sales Dasí, Emilio José (1997), «Feliciano de Silva y la tradición amadisiana en el Lisuarte de Grecia», Incipit, 17, pp. 175-217.

Silva, Feliciano de (2004), Amadís de Grecia, eds. Ana Carmen Bueno Serrano y Carmen Laspuertas Sarvisé, Alcalá de Henares, Centro de Estudios Cervantinos.

(2015), Florisel de Niquea (Partes I-II), ed. Linda Pellegrino, Alcalá de Henares, Universidad de Alcalá. 